\title{
ANÁLISE DAS ATIVIDADES DE PCP EM UMA INDÚSTRIA FARMACÊUTICA DO CENTRO OESTE MINEIRO
}

\author{
Thaís Teófilo Morais \\ Bacharel em Engenharia de Produção pelo UNIFOR-MG \\ E-mail: thaisteofilo_lp@hotmail.com \\ Samuel de Oliveira \\ Especialista em Ensino de Física \\ Mestre em Engenharia de Sistemas pela UFLA \\ Professor do UNIFOR-MG \\ E-mail: professor.samuel@yahoo.com.br
}

Recebido em: 06/02/2015

Aprovado em: 08/05/2015

\begin{abstract}
RESUMO
Este trabalho fundamenta-se na discussão sobre a importância da utilização do software integrado MRP II (Manufacturing Resources Planning), utilizado para gestão empresarial e o aperfeiçoamento do processo produtivo. Em qualquer organização o PCP (Planejamento e Controle da Produção) é essencial, pois direciona a produção, o controle e a distribuição. Como o objetivo principal do trabalho é analisar as atividades e identificar as dificuldades para um bom planejamento, fez-se uma pesquisa in loco em forma de estudo de caso. Esta foi realizada em uma indústria farmacêutica do interior de Minas Gerais, onde se identificou a existência de uma grande dificuldade em desempenhar as atividades de PCP, devido à deficiência do método utilizado para realização das previsões de demanda realizadas pelo setor comercial, local onde a previsão de venda se torna pouca assertiva. A partir disso, dificulta-se um bom planejamento, pois compromete a gestão de estoque de insumos e produto acabado. Os resultados apontam para que o software integrado MRP II seja eficiente para o planejamento e controle da produção, porém o fator impactante é o método falho para a elaboração das previsões de vendas, refletindo diretamente na programação. Apresenta-se como sugestão, revisão dos métodos utilizados para elaboração da previsão de demanda, a fim de contribuir para um bom planejamento da produção.
\end{abstract}

Palavras-Chave: Planejamento e Controle da Produção. Gestão de Estoque. Sistema MRP II.

\section{ANALYSIS OF PCP ACTIVITIES IN A PHARMACEUTICAL INDUSTRY IN THE MIDWEST OF MINAS GERAIS}

\begin{abstract}
This work is based on the discussion of the importance of using the integrated software MRP II (Manufacturing Resources Planning), used for business management and the improvement
\end{abstract}


of the production process. In any organization PCP (Planning and Control of Production) is essential because it directs the production, control and distribution. The main objective is to analyze the activities and the difficulties of good planning, the research was made in form of a case study, performed in a pharmaceutical company in Minas Gerais, where it was identified the existence of an great difficulty in performing the PCP activities due to method failure used to perform the demand forecasts made by the commercial sector, where the sales forecast becomes little assertive. From there, makes it difficult for good planning, because it jeopardizes the inventory management of raw materials and finished product. The results show that the integrated software MRP II is effective for planning and for production control, but striking factor is the flawed method for the preparation of sales forecasts, reflecting directly on schedule. It is presented as a suggestion, review of the methods used to prepare the demand forecast in order to contribute to a good production planning.

Keywords: Planning and Production Control. Inventory Management. MRP II system.

\section{INTRODUÇÃO}

A escolha da estratégia mais adequada para as organizações é um dos maiores desafios para as empresas. A melhoria dos processos organizacionais constitui-se na preocupação de qualquer empresa que tenha como objetivo central, manter a fidelidade de seus clientes e a conquista de seus produtos em novos mercados.

Para tal objetivo será necessário um bom planejamento e controle da produção, otimizando os processos produtivos e os estoques, incluindo os casos mais complexos como múltiplos produtos e estágios de produção. Uma das dificuldades de exercer um bom planejamento se dá, devido às incertezas de previsões de demanda, onde o setor de vendas não consegue cumprir corretamente com seu objetivo, a falta de produto ou a geração de estoque de produto acabado. Outro contratempo é a incerteza de fornecedores de matérias-primas e insumos que não cumprem com as datas de entregas solicitadas.

Uma abordagem para o planejamento e controle da produção bastante difundida nas empresas, está associada ao modelo ERP (Enterprise Resource Planning), esse sistema pode ser entendido que, além de controlar os recursos diretamente usados na manufatura, também permitem controlar os demais recursos da empresa utilizados na produção, comercialização, distribuição e gestão. O planejamento e controle da produção são fundamentais para o funcionamento da indústria e seu crescimento no mercado de trabalho. Pois permite uma visão integrada de suas atividades. Para tal, a utilização de software é um facilitador deste processo. 
O software é uma ferramenta integrada nas organizações que permite a execução de tal planejamento e acompanhamento da empresa, como a gestão de estoques e planejamento da produção, o acompanhamento e análise de todas as atividades da indústria. Mesmo com todas as vantagens da utilização do software no PCP como, por exemplo, a melhoria contínua da eficiência de produção e o cumprimento de metas, sabe-se que algumas empresas não utilizam seus recursos adequadamente para aperfeiçoar o processo produtivo.

A utilização de técnicas para melhoria no gerenciamento da demanda, através deste, terá uma contribuição para planejamento de produção mais eficiente, a fim de evitar geração e custos de estoques.

\section{PLANEJAMENTO E CONTROLE DA PRODUÇÃO}

A produção de bens de consumo teve início com a Revolução Industrial, quando foi possível produzir e criar meios para o consumo em massa. Os sistemas de PCP (Planejamento e controle da produção) evoluíram como fruto da evolução da própria ciência da Administração, desde os esforços de Frederick W. Taylor e Henry Fayol, na primeira década do século XX até os dias de hoje (QUELHAS, 2008, p. 1).

\footnotetext{
Com o avanço tecnológico do período pós-guerra (década de 1950), a complexibilidade dos bens produzidos cresceu consideravelmente, levando à necessidade de cálculos cada vez mais difíceis de serem realizados apenas pelo cérebro humano. Na década de 1960, os pesquisadores Joe Orlickey, Oliver Wight e G. W. Possl desenvolveram métodos similares para realizar esses cálculos, que foram compilados e divulgados no meio acadêmico sob uma mesma teoria: o MRP (Materials Requirements Planning)." (LUSTOSA et al, 2011, p. 1).
}

Araújo (2008) descreve planejamento como "atividades realizadas pela administração de uma organização, com o objetivo de definir quantidades a serem produzidas ou serviços disponibilizados", enquanto Cury (2000) aborda o planejamento e controle da produção como as atividades que integram e produzem condições para produção, atuando sobre o produto, recursos e produção. Alonga suas ações ou produz reflexos em toda a empresa, promovendo a produção através do acionamento das unidades de produção baseado em atividades coordenativas.

Segundo Molina (2006) o PCP é uma área criada dentro da gerência industrial, para dar suporte ao setor de produção, devendo administrar os recursos físicos e humanos necessários para garantir que os objetivos traçados pela empresa sejam alcançados. 
Para o nível estratégico ou corporativo do PCP são estabelecidos os objetivos e metas globais da empresa em longo prazo cujas decisões focam o que a empresa é hoje e o que ela pretende ser no futuro. São previstos nesse nível o direcionamento dos negócios, produtos, tecnologia, investimentos, recursos humanos, meio ambientes e a responsabilidade social. $\mathrm{O}$ nível estratégico deve ser elaborado pela alta direção da empresa para um período ideal de cinco anos, prevendo revisões anuais. "As atividades do PCP são exercidas nos três níveis hierárquicos de planejamento e controle das atividades produtivas de um sistema de produção" (TUBINO, 2000, p. 24).

No nível tático ou competitivo são determinadas as ações anuais de recursos e disponibilidades da empresa, com revisões mensais. Já no nível operacional ou funcional são administradas ações em curto prazo, é neste nível que é operacionalizado o planejamento e controle da produção envolvendo toda a sua logística.

\section{PLANEJAMENTO MESTRE DA PRODUÇÃO}

Segundo Tubino (2008) o planejamento mestre da produção é responsável por desmembrar os planos de produção estratégicos de longo prazo em planos característicos de produtos acabados para o médio prazo, a fim de direcionar as etapas de programação e execução das atividades operacionais da empresa. A partir desse planejamento, a empresa começa a assumir contratos de produção dos produtos acabados, fabricação das partes manufaturadas internamente, e da compra dos insumos produzidos pelos fornecedores externos. Assim o PMP exerce duas funções dentro da lógica do PCP: a primeira é direcionar a programação da produção para atender aos pedidos dos clientes em curto prazo. A segunda é permitir a análise e validação da capacidade do sistema produtivo em atender a demanda futura.

Segundo Corrêa, Gianesi e Caon (2001), a programação mestre por meio da aprimorada visão entre suprimento e demanda, permite oferecer aos clientes um adequado nível de serviço dentro das exceções impostas pelos níveis de estoques, recurso produtivo e tempos disponíveis. Os planos estratégicos devem ser quebrados em planos operacionais táticos: planos que definem o que realmente deve ser feito. Estes se focalizam nos problemas da empresa em níveis mais operacionais:

- Plano de vendas: quantidade que os representantes de vendas deverão esforçar-se para vender; 
MORAIS, T. T.; OLIVEIRA, S. Análise das atividades de PCP em uma indústria farmacêutica do Centro-Oeste mineiro

- Plano de marketing: mercados a enfrentar, produtos, preços, promoções e esquemas de distribuição que serão utilizados;

- Plano de engenharia: programas e projetos a serem desenvolvidos na prancheta;

- Plano de finanças: receitas, orçamentos de despesas e margens de lucros;

- Plano de manufatura: o que, quanto, quando e como produzir.

Esses planos operacionais devem estar ligados uns aos outros, e a todos os planos estratégicos da empresa. As decisões devem ser comuns entre os departamentos.

Tubino (2008) descreve que na montagem do plano-mestre de produção, utilizam-se tabelas de dados com as informações detalhadas de cada período dos itens a ser planejado, constando informações sobre a demanda prevista, o recebimento programado, os estoques iniciais e projetados, a necessidade líquida e o plano-mestre de produção para cada período analisado. Na FIG. 1, segue modelo de registro básico de MPS.

Figura 1 - Registro básico do MPS

\begin{tabular}{l|l|l|l|l|l|l}
\hline \multicolumn{1}{c|}{ ITEM DE MPS ELPRAZOL } & Atraso & 1 & 2 & 3 & 4 & 5 \\
\hline Previsão de demanda independente & & & & & & \\
\hline Demanda dependente & & & & & & \\
\hline Pedidos em carteira & & & & & & \\
\hline Demanda total & & & & & & \\
\hline Estoque projetado disponível & & & & & & \\
\hline Disponível para promessa & & & & & & \\
\hline Programa-mestre de produção MPS & & & & & & \\
\hline
\end{tabular}

Fonte: Corrêa, Gianesi e Caon (2009)

Cada coluna do registro contém todas as atividades referentes à programação-mestre, esperadas para acontecer em um determinado período.

As quatro primeiras linhas do registro mostrado na FIG. 1 são referentes à demanda.

1. Previsão de demanda independente: é a previsão de demanda que esperamos, ocorrerá de forma independente da demanda de qualquer outro item no sistema. Refere-se à demanda que o mercado consumirá, com os itens sendo vendidos diretamente ao cliente. Para produtos acabados, indica à previsão de demanda normal.

2. Demanda dependente: identifica as quantidades do item em questão que serão vendidos no futuro, como parte de algum outro produto. É registrada a necessidade 
MORAIS, T. T.; OLIVEIRA, S. Análise das atividades de PCP em uma indústria farmacêutica do Centro-Oeste mineiro

bruta do item a ser produzido e que devem estar disponíveis para suprir o setor subsequente. Portanto quanto maior for a demanda maior será a necessidade do item.

3. Pedidos em carteira: referem-se a ordens de clientes de produtos que já foram vendidos, porém não foram ainda despachados.

4. Demanda total: essa linha representa a combinação das três anteriores. Alguns sistemas MRP comerciais fazem com que a Demanda Total, seja a soma das demandas: independente, dependente e carteira.

5. Estoque projetado disponível: essa linha projeta a quantidade que vai estar disponível em estoque do item de MPS em questão, em determinado momento futuro.

6. Disponível para promessa: essa linha é usada para suportar o processo de promessa de datas e quantidades para clientes e projeta o suprimento de produtos menos os pedidos em carteira.

7. Programa-mestre de produção - MPS o lado dos suprimentos: essa é a linha para que se coloquem ordens para que a demanda de cada período seja adequadamente atendida, tempo a tempo. As ordens de suprimento do programador-mestre podem aparecer de três formas:

- Ordens Liberadas (OL): disparam os processos produtivos, autorizando utilização dos insumos e recursos de produção para produzir determinado produto.

- Ordens Firmes Planejadas (OFP): é uma declaração do programadormestre, onde o mesmo pretende produzir tal produto na data prevista, porém não considera hora certa de liberar essa ordem para produção.

- Ordens Planejadas (OP): é uma versão computacional da OFP, devido volume de cálculo envolvido, seria impossível pelo programador-mestre gerar todas as sugestões e revisões de abertura de ordens com a rapidez necessária.

Após a elaboração do PMP (Programa Mestre de Produção), é feita uma análise e confirmação da capacidade produtiva, com o objetivo de identificar algum período com produção insuficiente de produtos finais, ou com produção prevista acima da capacidade tornando assim necessário fazer a revisão do PMP. Tubino (2000) descreve que a sistemática 
do planejamento-mestre da produção consiste em gerar o PMP inicial que será testado frente as suas necessidades de capacidade produtiva para verificar sua viabilidade e autorizar seu prosseguimento. Os passos da rotina para análise da capacidade produtiva do PMP são:

a) Identificar os recursos a serem incluídos na análise (gargalos);

b) Obter o modelo de consumo, ou taxa de produção no caso de máquina, de cada produto acabado incluído no PMP para cada recurso;

c) Multiplicar o modelo de consumo de cada produto para cada recurso pela quantidade prevista para o período em função do lead times de planejamento;

d) Consolidar as necessidades de capacidade para cada recurso em cada período;

e) Comparar as disponibilidades dos recursos com as necessidades de capacidades calculadas em cada período para tomada de decisão quanto à viabilidade do PMP.

\section{MRP II - MANUFACTURING RESOURCES PLANNING}

Corrêa e Gianesi (1993) afirmam que o MRP-II é um sistema hierárquico de administração da produção, em que os planos de longo prazo da produção são detalhados desde o início até se chegar ao nível do planejamento de componentes e máquina específicas.

\footnotetext{
A intenção inicial do MRP II era planejar e monitorar todos os recursos da empresa - produção, marketing, finanças e engenharia - através de um sistema fechado que gerava análises financeiras. A segunda intenção importante do conceito MRP II era estimular o sistema de produção (DAVIS; AQUILANO; CHASE, 2001, p. 516).
}

Segundo Tubino (1997) os modelos de estoques baseados na lógica do MRP são modelos normalmente incorporados a um sistema de informações gerenciais, mais amplo, conhecido como MRP-II (Manufacturing Resource Planning) que busca, via informatização do fluxo de informações, integrar os diversos setores da empresa como marketing, engenharia e finanças ao sistema de produção.

A lógica do MRP II está estruturada em seis módulos:

1. PP - Planejamento da produção (Production Planning):

2. Planejamento mestre da produção (Master production schedule).

3. PMP - Plano mestre da produção (Master Production Plan).

4. MRP I - Planejamento das necessidades de materiais (Material Requirements Planning). 
MORAIS, T. T.; OLIVEIRA, S. Análise das atividades de PCP em uma indústria farmacêutica do Centro-Oeste mineiro

5. CRP - Cálculo de requisitos de capacidade (Capacity Requirements Planning): O módulo CRP calcula, período por período, as necessidades de capacidade produtiva, de forma detalhada, permitindo a identificação de ociosidades ou excesso de capacidade e possíveis insuficiências.

6. SFC - Controle de fábrica ou de produção (Shoop floor control): Controle de Fábrica é responsável pela sequenciação das OP's (Ordens de Produção), dentro de um período de planejamento e controle, no nível do chão de fábrica. É este módulo que busca garantir que o que foi planejado será executado. O Roteiro de produção e a lead-times de cada item são as principais entradas do módulo.

Para o sucesso da aplicação do MRP II, precisam estar perfeitamente definidas as estruturas dos produtos (nem sempre adequadamente formalizadas), as informações sobre a disponibilidade de materiais fornecidos a tempo e com precisão absoluta, e os parâmetros da Gestão de Estoques devem ser, tanto quanto possível, respeitados (RUSSOMANO, 2000, p. 200).

O fluxo de informações que caracterizam o sistema MRP II é apresentado na FIG. 2.

Figura 2 - Sistema MRP II

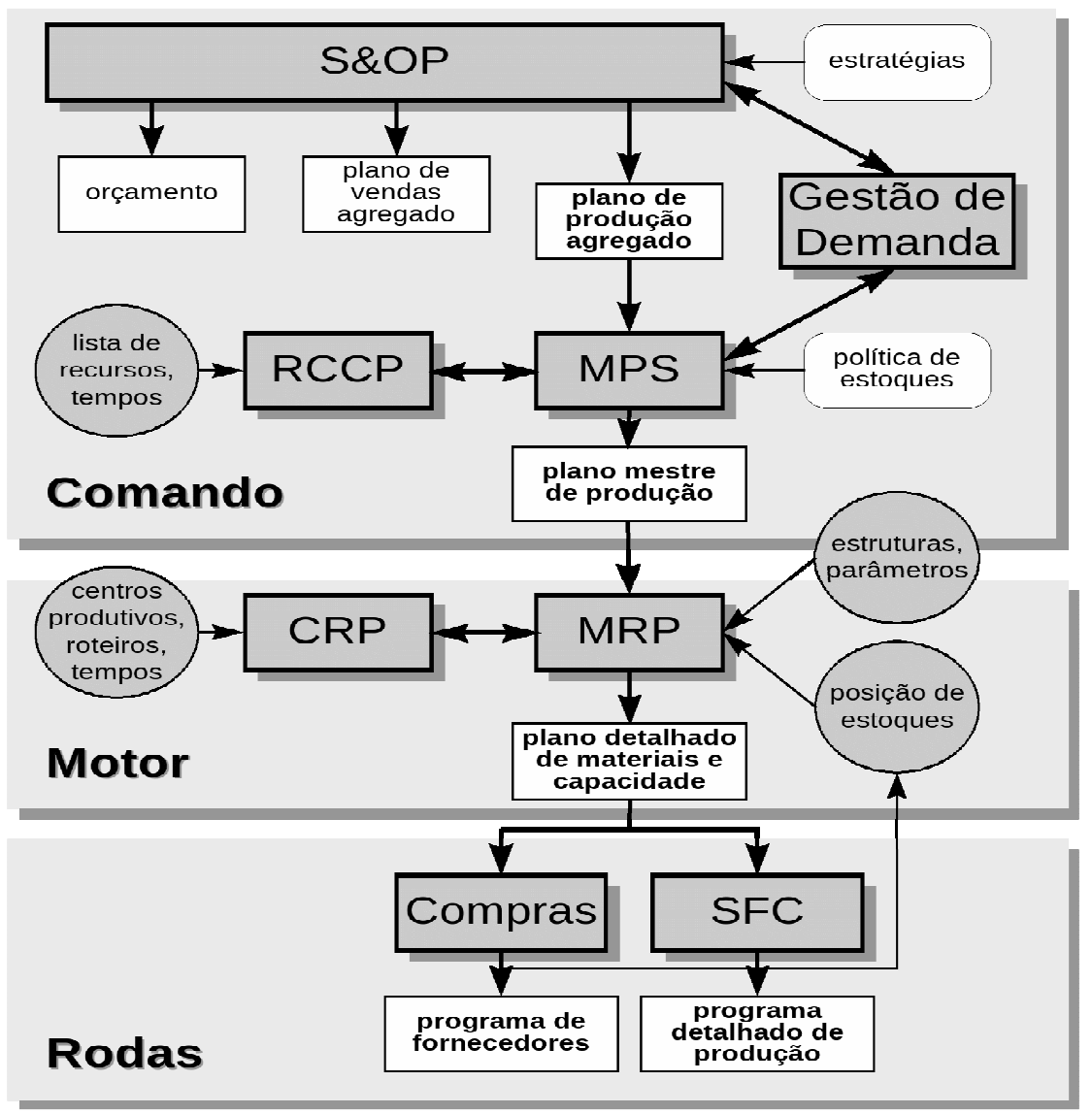

Fonte: Corrêa; Gianesi e Caon (2009). 


\section{DESENVOLVIMENTO}

O objeto do presente estudo foi uma indústria de medicamentos genéricos, situada no centro-oeste de Minas Gerais. A indústria produz medicamentos nas áreas semissólidos (cremes, pomadas, loções e géis), sólidos orais (comprimidos, comprimidos revestidos, pós para suspensão oral, drágeas, cápsulas) e injetáveis de pequeno volume, com um portfólio atuante nas Linhas Genéricos de marca, Genéricos, MIP e Hospitalar. Sua missão é oferecer, em todo território nacional, uma diversificada linha de medicamentos genéricos de alta confiabilidade e eficácia, proporcionando a satisfação de seus clientes e consumidores bem como o desenvolvimento de seus colaboradores e sociedade.

Realizou-se a coleta de dados através de relatórios fornecidos pelo sistema integrado TOTVS, um software de gestão utilizado pela empresa. Os relatórios fornecem dados de estoque e vendas que correspondem um período de 12 meses, referente a Julho de 2013 a Junho de 2014.

A seleção da amostra para análise do trabalho em questão foi realizada a partir dos seguintes critérios:

- Classificação dos produtos através da Curva ABC;

- Análise da previsão de demanda fornecida pelo setor comercial através de relatórios;

- Inclusão da previsão de demanda no PMP;

- Aplicação do MRP no PMP.

A partir dos resultados compara-se:

- Relatórios de venda programada e venda praticada, através de planilhas e gráficos apresentados no Software Microsoft Excel 2013.

- Verifica-se a produtividade dos produtos que foram programados no PMP.

- Verifica-se a eficiência no controle de estoque de insumos e produto acabado.

A programação de produção é realizada através do objetivo de venda informado pelo setor comercial. Os dados fornecidos são lançados na planilha PMP, verificando-se qual a quantidade a ser produzida de cada produto. A partir dessas informações são inseridas no 
software MRP II TOTVS, que realiza a sua explosão obtendo assim, os insumos a serem utilizados, bem como, a quantidade de cada produto, considerando o estoque atual e também o custo de compra dos itens em falta.

O relatório final apresenta as seguintes informações:

- Nome fantasia - nome do insumo conforme cadastro no sistema.

- Código do produto - código conforme cadastro no sistema.

- Estoque Disponível - estoque atual.

- Período - período informado na programação pode ser classificado em semanas ou meses.

- Necessidade Bruta - quantidade necessária de cada insumo.

- Quantidade comprada - pedidos existentes de cada insumo.

- Necessidade Líquida - quantidade faltante de cada item, considerando o estoque atual e pedidos em aberto.

- Custo - valor de compra de todos os insumos em falta.

A partir do relatório final, analisa-se o mesmo verificando qual a necessidade de estar lançando requisições de compra no sistema. Para tal atividade será necessário considerar leadtime de cada um dos itens em falta.

Os 10 produtos estudados são: Azitromicina, Claritromicina, Cloridrato de Lidocaína, Digoxina, Dipropionato de Betametasona, Maleato de Enalapril A e B, Omeprazol A e B, os mesmos foram extraídos através da curva $\mathrm{ABC}$, eles representam a classe A referente ao valor de faturamento da empresa.

No GRAF. 1 e 2 as previsões de vendas referentes aos 10 produtos estudados apresentam um índice de assertividade pequeno, onde o setor de vendas não consegue cumprir com o objetivo informado, sempre vendendo acima ou abaixo do prometido, ou seja, sempre haverá falta de produto ou alto volume de estoque. 
Gráfico 1 - Previsão de vendas x praticado - Linha Farma

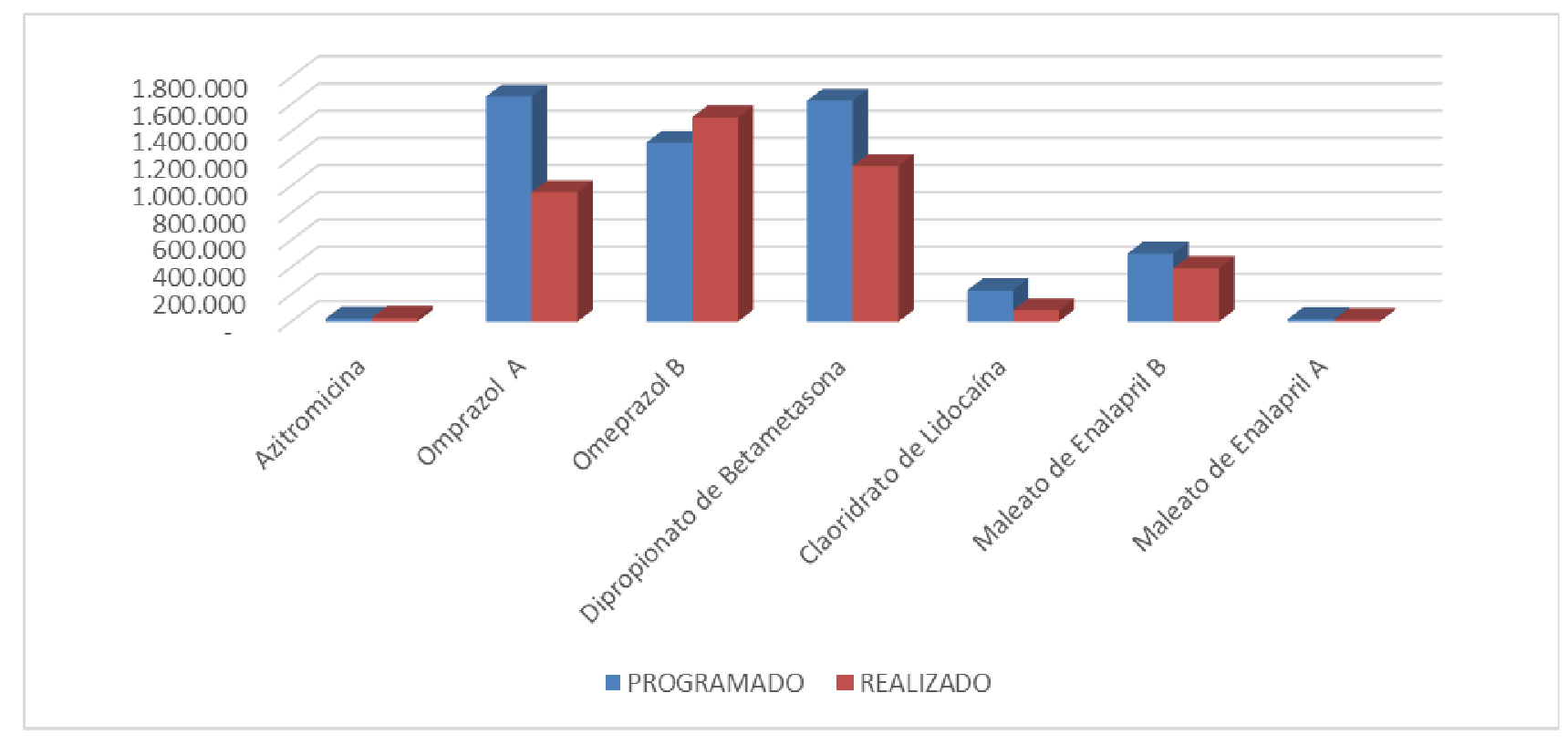

Fonte: Dados da pesquisa.

Gráfico 2 - Previsão de vendas x praticado - Linha Hospitalar

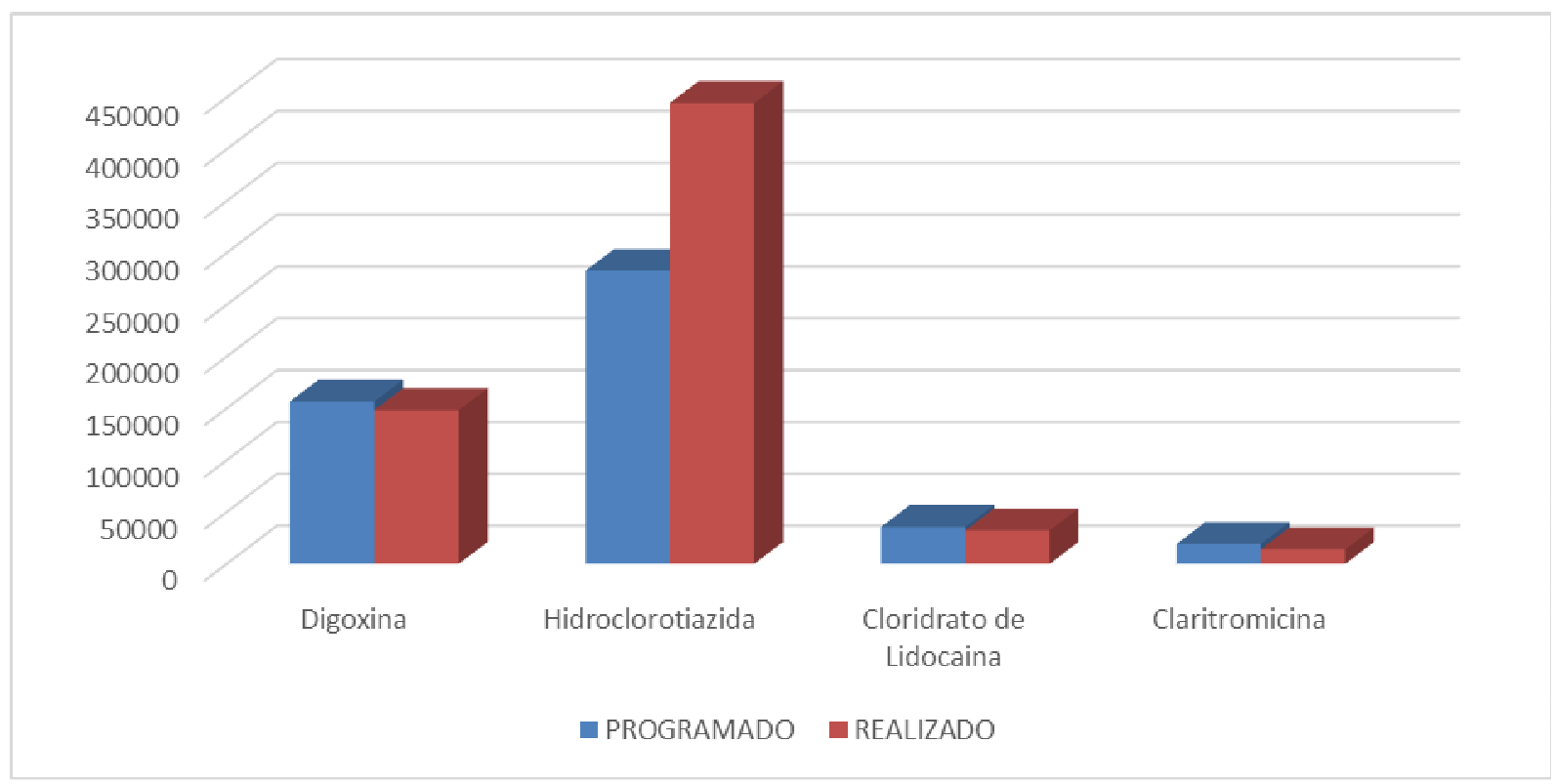

Fonte: Dados da pesquisa.

É possível identificar que tanto na linha farma quanto na linha hospitalar os objetivos não são cumpridos, não sendo possível realizar o planejamento conforme programado, pois o planejamento visa a produção em campanha; evitando que produza os mesmos produtos todos os meses. 
MORAIS, T. T.; OLIVEIRA, S. Análise das atividades de PCP em uma indústria farmacêutica do Centro-Oeste mineiro

O GRAF. 3 mostrado a seguir representa a razão entre a venda praticada em relação ao objetivo de vendas.

Gráfico 3 - Porcentagem de vendas sobre o objetivo

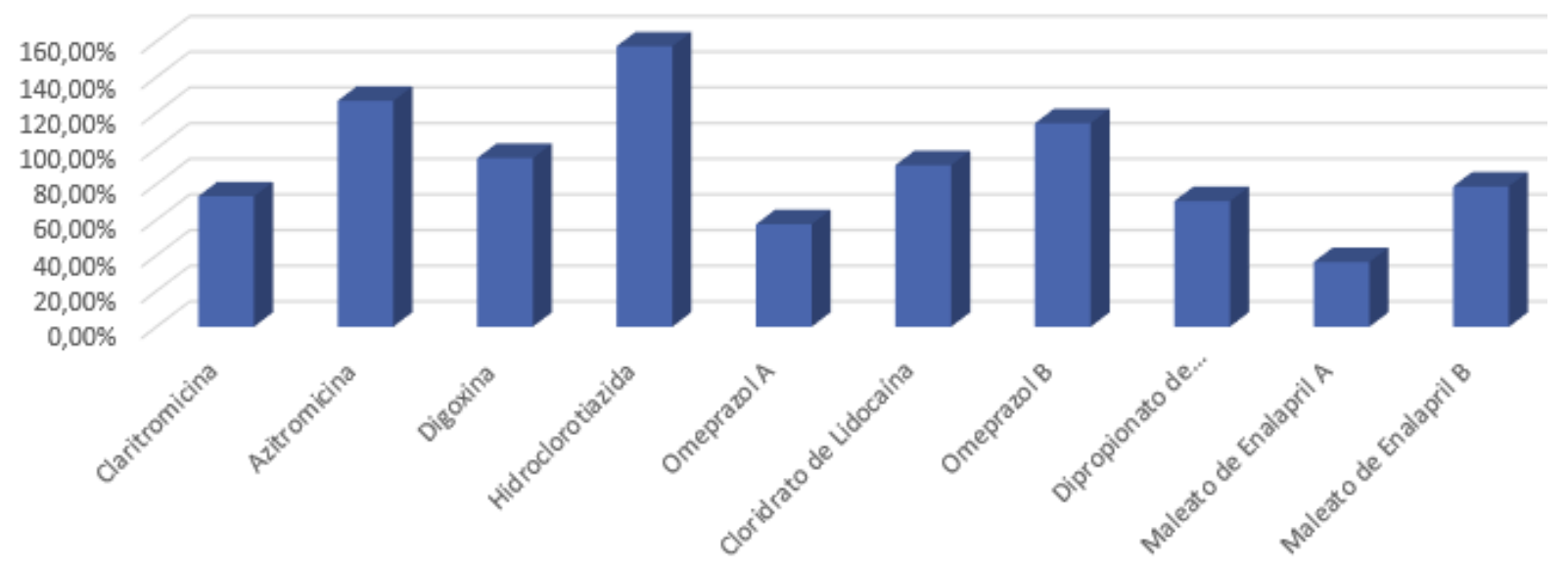

Fonte: Dados da pesquisa.

O produto Maleato de Enalapril A, teve uma razão de $20 \%$ entre a venda praticada e o objetivo de vendas, o setor comercial deve informar um objetivo mais realista, e alterar seus objetivos quando os mesmos não foram cumpridos.

Já o produto Hidroclorotiazida cumpriu com objetivo de venda e superou $40 \%$ das vendas. Devido à superação das vendas foi necessária a utilização do estoque de segurança. Como o estoque de segurança foi reduzido, na próxima programação será repassado ao setor comercial a redução. O objetivo informado pelo comercial deveria ser mais realista.

No GRAF. 4 e 5 foi realizada uma comparação de produção versus vendas dos produtos estudados. 
Gráfico 4 - Produção x Vendas- Linha Farma

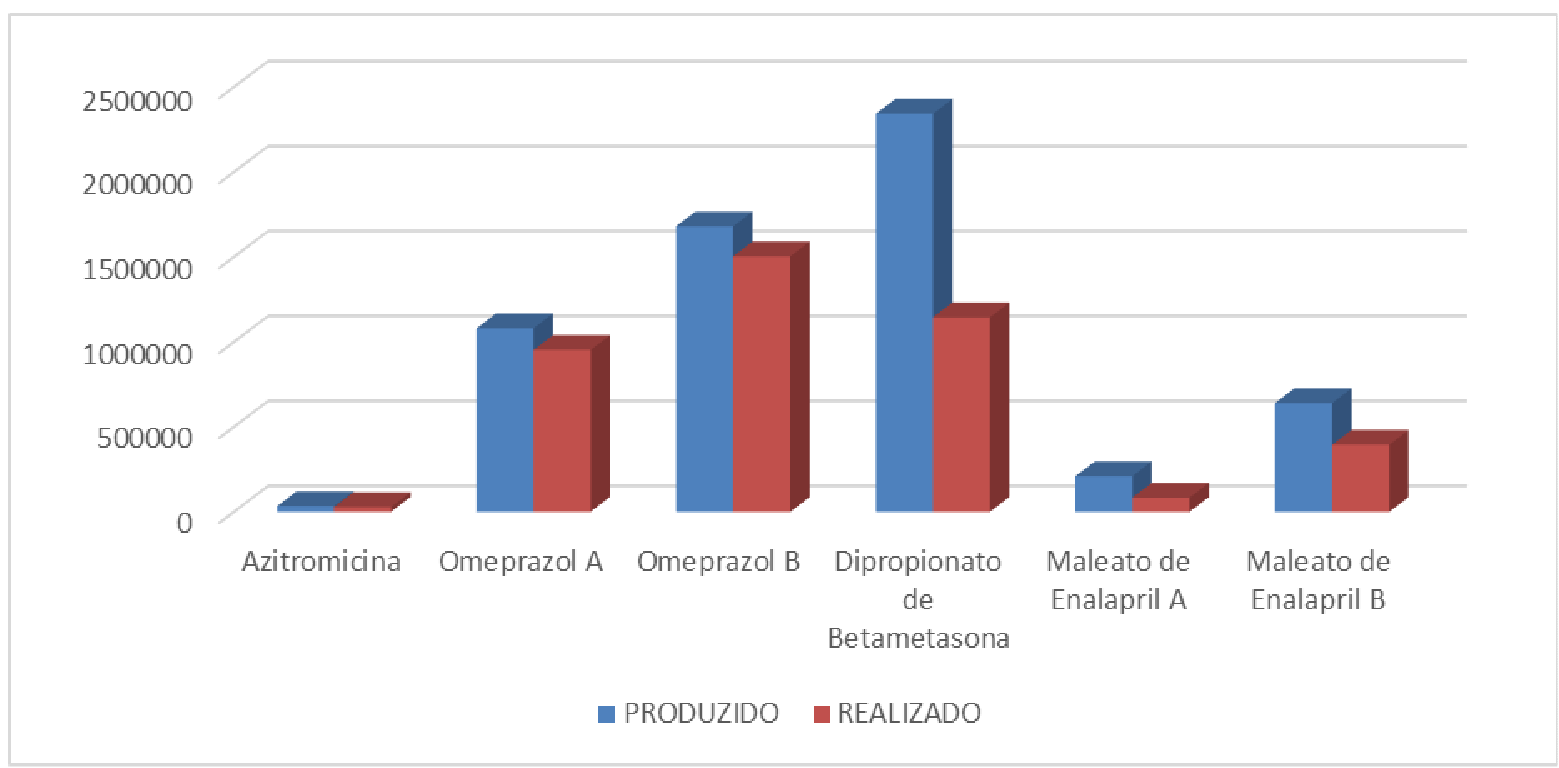

Fonte: Dados da pesquisa.

Gráfico 5 - Produção x Vendas - Linha Hospitalar

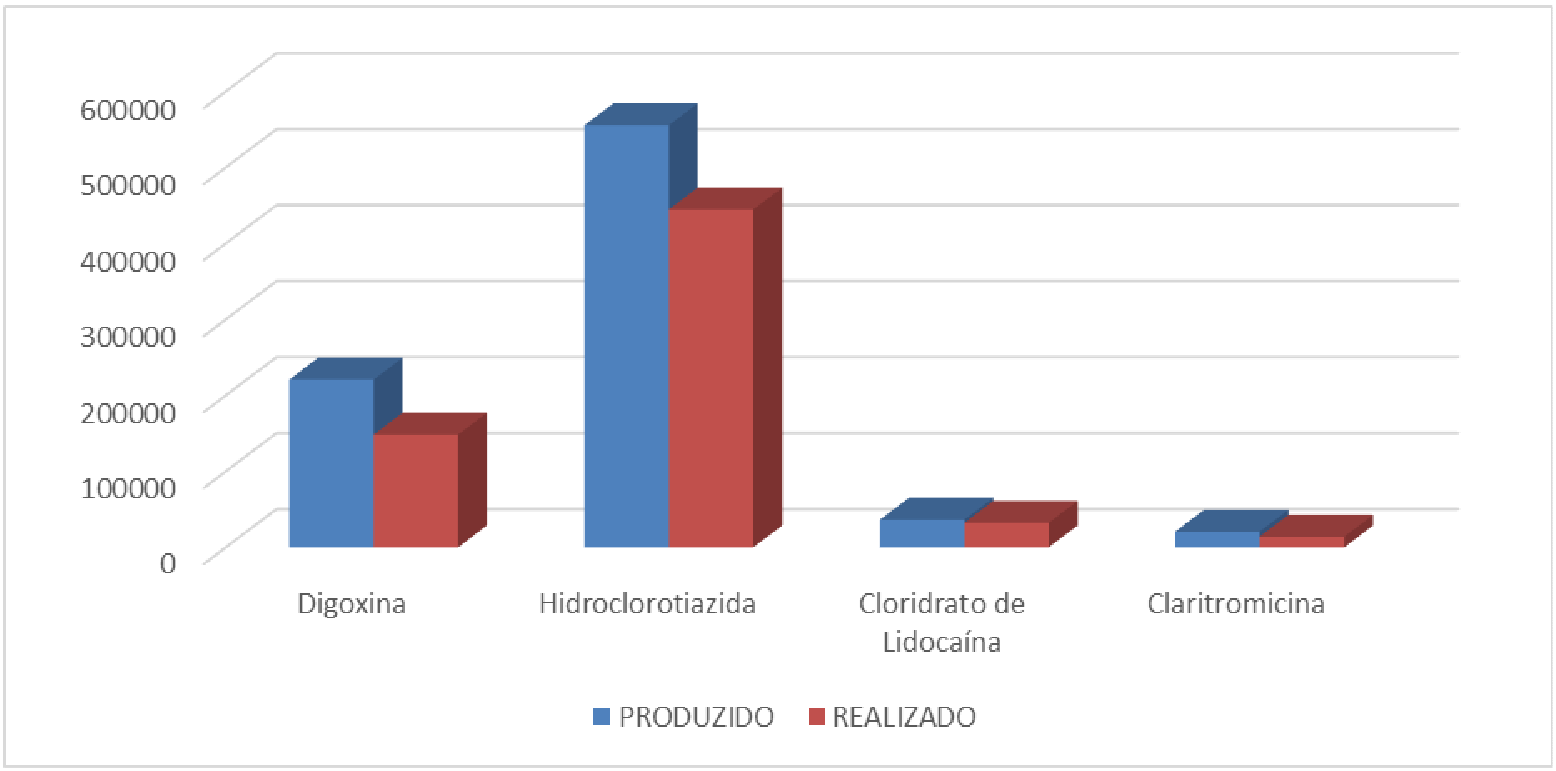

Fonte: Dados da pesquisa.

É possível verificar que a produção atenderia os objetivos de venda de todos os produtos apresentados nos GRAF. 4 e 5. Por exemplo o produto Azitromicina, foi vendido praticamente toda a produção, e por falta de capacidade produtiva não é possível aumentar a produção, bem como o objetivo. A única forma de aumentar o faturamento deste produto seria a compra de mais um equipamento. 
MORAIS, T. T.; OLIVEIRA, S. Análise das atividades de PCP em uma indústria farmacêutica do Centro-Oeste mineiro

Já o produto Hidroclorotiazida, a produção é realizada para formação de estoque de 3 meses, mas como o setor de vendas sempre supera o seu objetivo, não é possível realizar estoque desse produto. Como sugestão, o setor comercial deveria alterar a previsão de vendas.

O produto Maleato de Enalapril não conseguiu atingir o objetivo de vendas, devido à falta de capacidade de secagem no montante do período estudado. Atualmente, uma nova estufa para secagem do produto foi adquirida e está sendo possível atender a previsão de demanda.

Foi analisado o estoque dos ativos e estoque de produto acabado dos 10 produtos estudados, a fim de verificar se é eficiente o método de previsão de vendas e controle de estoque. A seguir são mostrados os ativos dos produtos estudados, com a quantidade em estoque, o consumo mensal, o custo total do insumo e o tempo de estoque de cada um deles.

Tabela 1 - Análise de estoque dos ativos

\begin{tabular}{c|c|c|c|c}
\hline Insumo & $\begin{array}{c}\text { Estoque } \\
(\mathrm{kg})\end{array}$ & $\begin{array}{c}\text { Consumo } \\
\text { Mensal }(\mathrm{kg})\end{array}$ & Custo (R\$) & $\begin{array}{c}\text { Tempo de } \\
\text { Estoque } \\
(\mathrm{meses})\end{array}$ \\
\hline Claritromicina & 2.761 & - & 1.396 .054 & - \\
\hline Maleato de Enalapril & 844 & 66 & 122.961 & 12,8 \\
\hline $\begin{array}{c}\text { Dipropionato de } \\
\text { Betametasona }\end{array}$ & 39 & 3 & 212.961 & 12,8 \\
\hline Cloridrato de Lidocaína & 1.240 & 115 & 95.232 & 10,78 \\
\hline Digoxina & 12 & 4 & 157.041 & 3 \\
\hline Omeprazol & 9.168 & 2.171 & 214.542 & 4,22 \\
\hline Hidroclorotiazida & 2.214 & 620 & 71.309 & 3,57 \\
\hline Azitromicina & 4.603 & 233 & 1.184 .558 & 19,75 \\
\hline
\end{tabular}

Fonte: Dados da pesquisa.

Conforme a TAB. 1 é possível identificar que não existe uma regra para controle de estoque, o tempo desses estoques são instáveis, devido a constantes mudanças no objetivo de venda. A programação de produção é realizada para quatro meses, considerando o mês vigente mais os próximos três meses e os objetivos são alterados mês a mês. Com isso fica inviável ter em estoque a quantidade ideal de cada insumo.

Verifica-se também que o valor dos estoques de apenas 8 insumos de um universo de 190 itens é muito alto, totalizando R $\$ 3.454 .159,53$. Sabendo que o valor total dos insumos representa $\mathrm{R} \$ 6.104 .336,43$.

No GRAF. 6 é possível verificar que existe uma diferença grande entre o custo da compra dos insumos, através do objetivo, que é informado pelo setor comercial, com o custo 
MORAIS, T. T.; OLIVEIRA, S. Análise das atividades de PCP em uma indústria farmacêutica do Centro-Oeste mineiro

da compra de acordo com o que foi realizado. Se o objetivo fosse mais realista não teriam grandes quantidades de insumos em estoque e custo do estoque não estaria tão elevado.

Gráfico 6 - Custo da compra de insumos em $(\mathrm{R} \$)$

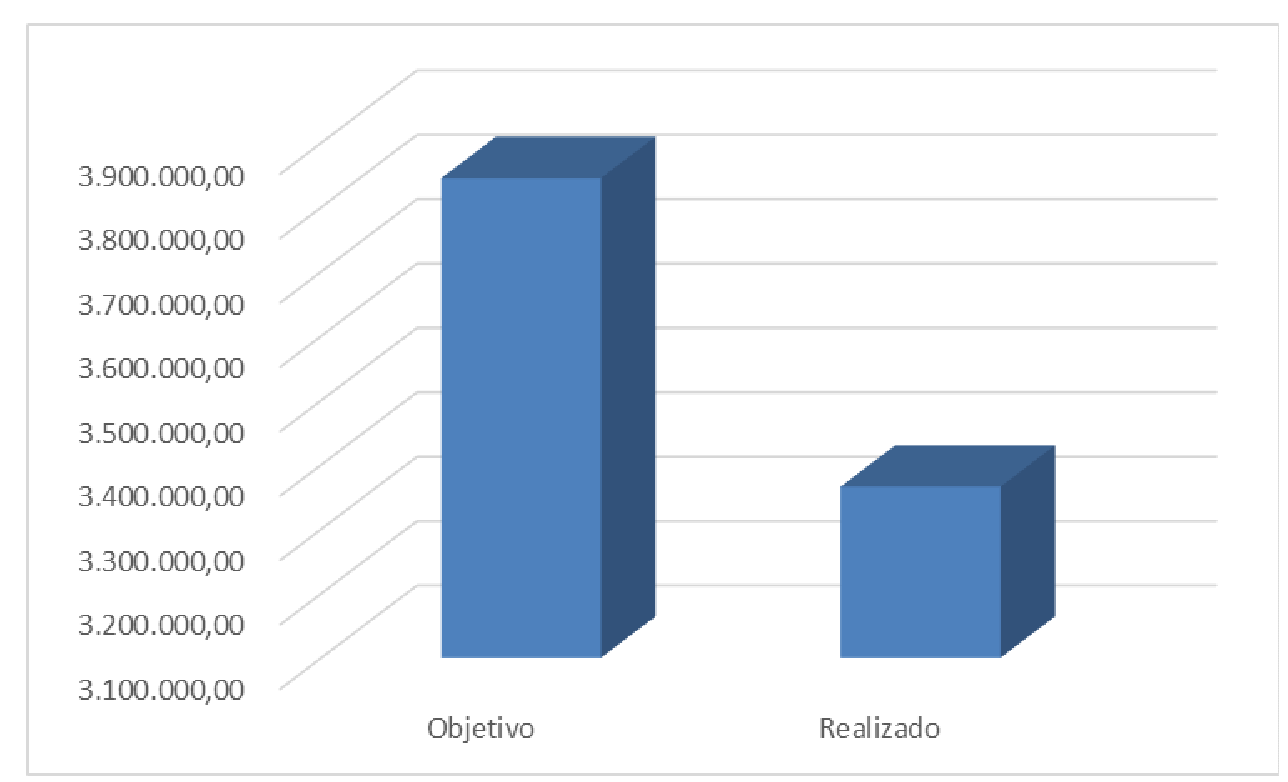

Fonte: Dados da pesquisa.

A partir do GRAF. 6 é possível identificar uma diferença de $\mathrm{R} \$ 560.000,00$ no valor de compra através do objetivo e através das vendas praticadas. Foram inseridas no sistema integrado TOTVS as quantidades informadas pelo objetivo e as quantidades vendidas, a fim de verificar o custo de compra dos itens faltantes de cada uma e a partir disso fazer essa comparação.

A seguir no GRAF. 7 e 8 é apresentado o estoque de produto acabado da Linha Farma e Hospitalar. 
Gráfico 7 - Estoque Produto Acabado - Linha Farma

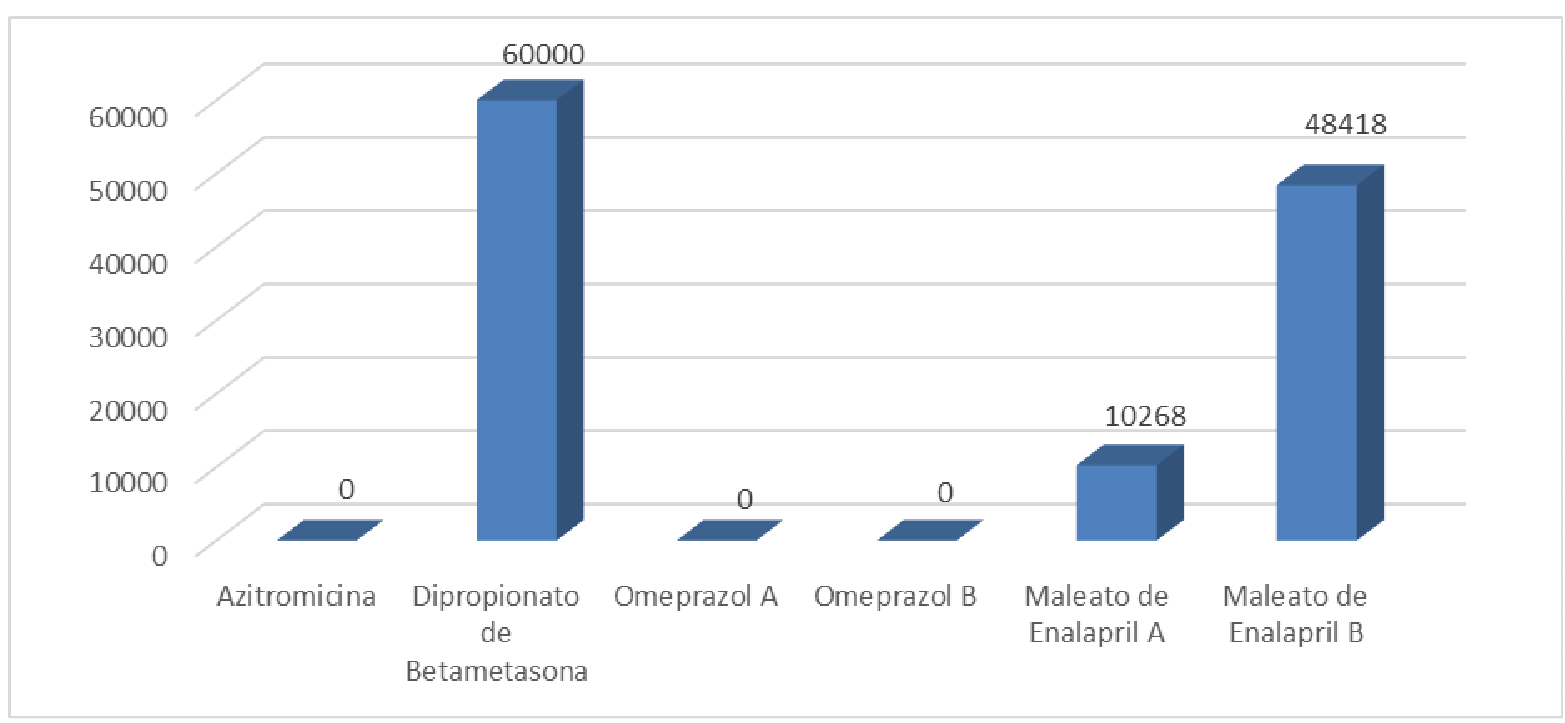

Fonte: Dados da pesquisa.

Gráfico 8 - Estoque Produto Acabado - Linha Hospitalar

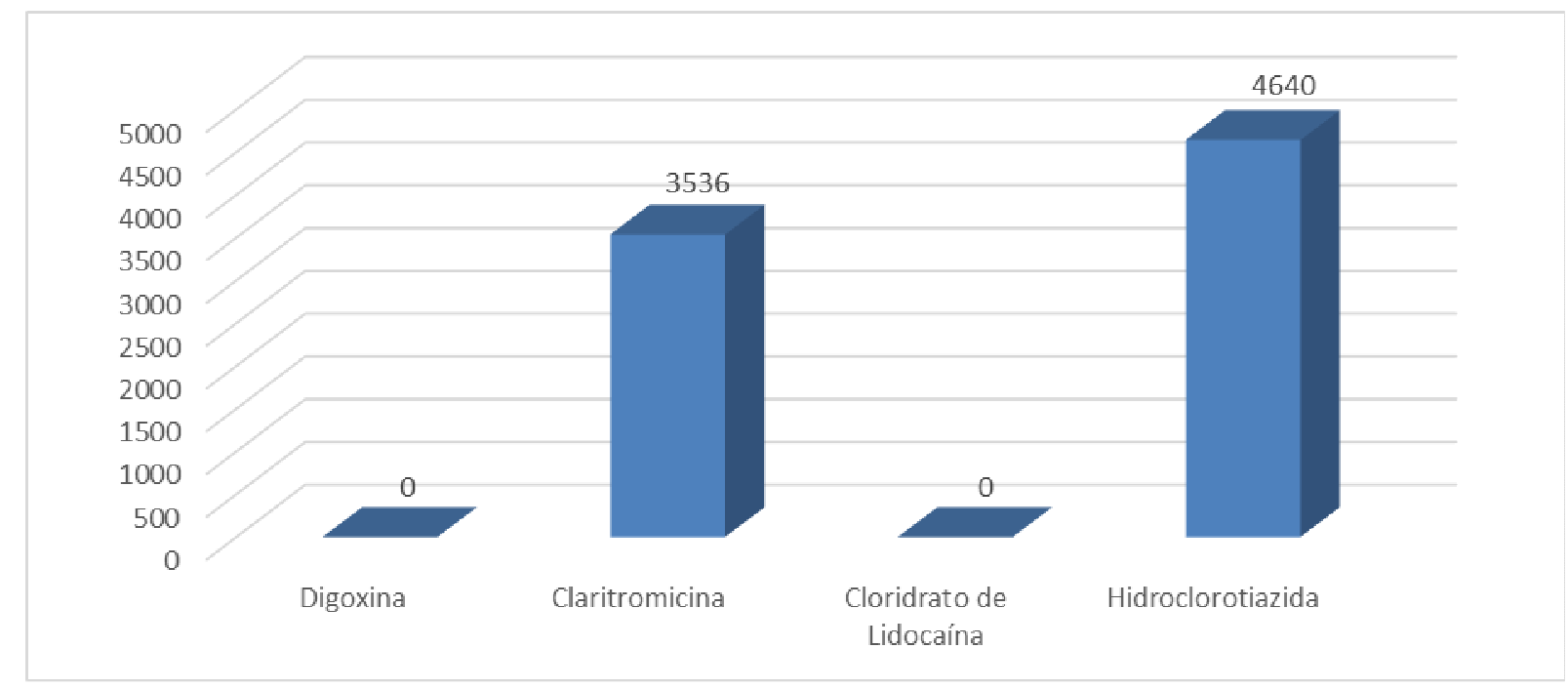

Fonte: Dados da pesquisa.

Os estoques de produtos acabados foram analisados no fim do período estudado, julho de 2014. Foi verificado que 5 produtos não havia no estoque, e que a produção naquele mês seria para venda do mês vigente. Para esses produtos não é possível produzir para gerar estoque, devido a falta de capacidade produtiva nos setores de Pó Suspensão (Azitromicina), Semissólidos (Cloridrato de Lidocaína) e Cápsulas (Omeprazol A e B). Já para o produto Digoxina, tem-se dificuldade em adquirir a matéria-prima, pois a mesma é importada da Índia e tem um processo burocrático para sua liberação, gerando atraso no processo produtivo. 
MORAIS, T. T.; OLIVEIRA, S. Análise das atividades de PCP em uma indústria farmacêutica do Centro-Oeste mineiro

Conforme se verifica na TAB. 2, os produtos que existem estoques são produzidos no mês de acordo com a necessidade, iniciando pelos produtos que ainda não tem estoque para venda do mês vigente. Normalmente, é realizada a produção em campanha a fim de ter pelo menos três meses de estoque de cada produto, para no mês seguinte não ter a mesma produção novamente. Assim, é possível que na linha de produção entrem todos os produtos ativos e tenha estoque disponível para o setor comercial.

Tabela 2 - Tempo de Estoque Produto Acabado (meses)

\begin{tabular}{c|c}
\hline Produto & Tempo de Estoque \\
\hline Dipropionato de Betametasona & 0,18 \\
\hline Maleato de Enalapril A & 0,53 \\
\hline Maleato de Enalapril B & 1,16 \\
\hline Claritromicina & 2,21 \\
\hline Hidroclorotiazida & 0,20 \\
\hline
\end{tabular}

Fonte: Dados da pesquisa.

A seguir, o GRAF. 9 apresenta o tempo de estoque dos principais insumos, e é possível identificar que não existe um tempo de estoque definido. Por exemplo, o insumo Claritromicina, se tornou obsoleto, devido à perda de registro do produto. Portanto, esse insumo refere-se a um valor de $\mathrm{R} \$ 1.396 .054$.

Gráfico 9 - Tempo de estoque de insumos (meses)

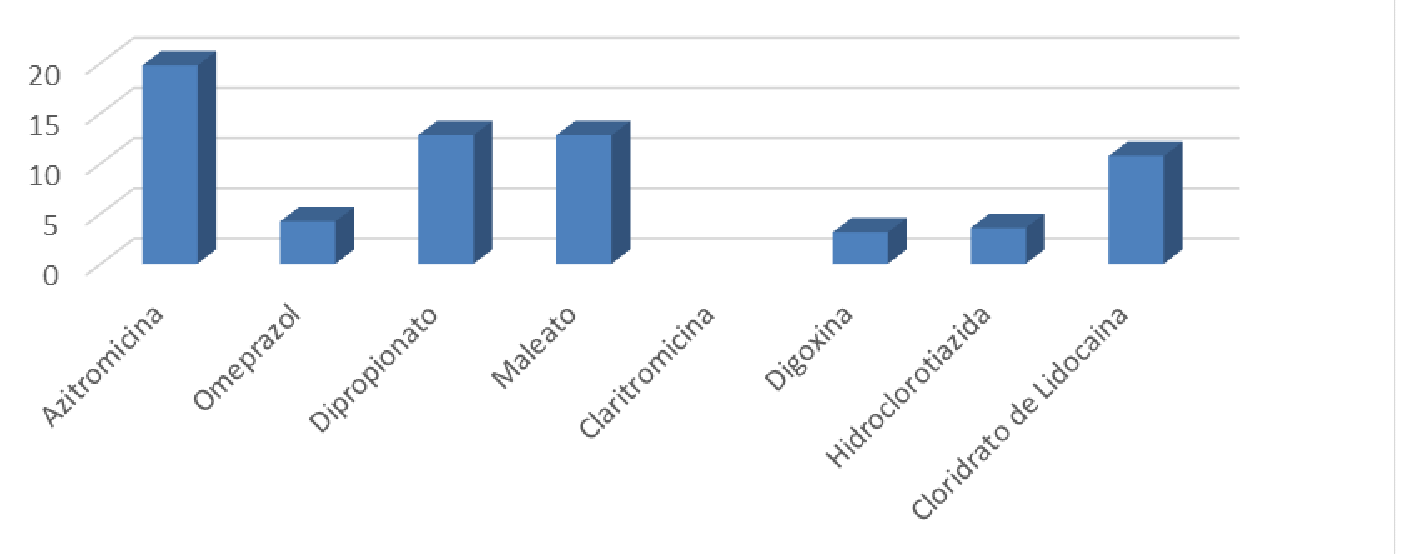

Fonte: Dados da pesquisa.

O problema citado se dá devido às incertezas nos objetivos de venda, pois a programação de compra é realizada através dessas informações. Quando as mesmas não são cumpridas geram estoques sem necessidade, gerando custos de requerimento dos mesmos e 
MORAIS, T. T.; OLIVEIRA, S. Análise das atividades de PCP em uma indústria farmacêutica do Centro-Oeste mineiro

manutenção dos estoques. Além disso, os insumos até vencem no estoque, tendo que solicitar o descarte, o que aumenta mais ainda o custo de estoque.

A estratégia adotada pela empresa de produzir e realizar compras através dos objetivos pode ser um sério risco que a empresa pode sofrer, pois, como foi verificada, a assertividade de vendas versus objetivo pelo setor comercial é pequena. Portanto, se o setor comercial vende além do objetivo de um determinado produto que existe restrição na compra de insumos, como por exemplo, um item for adquirido via importação marítima e seu lead-time for de 90 dias, nos próximos meses não terá estoque desse produto. Isso por a compra ter sido realizada de acordo a previsão. O faturamento da empresa tem grande possibilidade de aumentar, mas, para isso, é necessário um bom planejamento e previsão de demanda mais realista. Um método sugestivo seria a utilização de novos métodos de previsão de demanda juntamente com o setor comercial a fim de ter informações mais precisas.

\section{CONCLUSÃO}

Conclui-se que o software MRPII é eficiente para o planejamento e controle da produção, porém, o fator impactante é o método falho para a elaboração das previsões de vendas, refletindo diretamente na programação, onde as dificuldades seriam os métodos ineficientes utilizados pelo setor comercial durante a realização das previsões de vendas. Tal deficiência impacta diretamente no planejamento e controle da produção, pois a produção e a compra de materiais são realizadas com base nas previsões de demanda. Essa deficiência compromete diretamente na gestão de estoques e custos.

\section{REFERÊNCIAS}

ARAÚJO, M. A. Administração de produção e operações: uma abordagem prática. Belo Horizonte: Armazém de Ideias, 2008.

CORRÊA, H. L.; GIANESI, I. G. N. Just in Time, MRPII e OPT: um enfoque estratégico. 2. ed. São Paulo: Atlas, 1993.

CORRÊA, H. L.; GIANESI, I. G. N.; CAON, M. Planejamento, programação e controle da produção: MRPII/ERP, conceitos, uso e implantação. 4. ed. São Paulo: Atlas, 2001.

CURY, A. Organização e métodos: uma visão holística. 7. ed. rev. e ampl. São Paulo: Atlas, 2000. 
MORAIS, T. T.; OLIVEIRA, S. Análise das atividades de PCP em uma indústria farmacêutica do Centro-Oeste mineiro

DAVIS, M. M.; AQUILANO, N. J.; CHASE, R. B. Fundamentos da administração da produção. Porto Alegre: Bookman, 2001.

LUSTOSA, L. et al. Planejamento e controle da produção. Rio de Janeiro: Campus, 2011.

MOLINA, C. C.; RESENDE, J. B. Atividades do planejamento e controle da produção (PCP). Revista científica eletrônica de administração, ano 6, n. 11, dez. 2006.

QUELHAS, O. Planejamento e controle da produção. São Paulo: Elsevier, 2008.

TUBINO, D. F. Manual de planejamento e controle da produção. São Paulo, Atlas, 1997.

TUBINO, D. F. Manual de planejamento e controle da produção. São Paulo: Atlas, 2000.

TUBINO, D. F. Planejamento e controle da produção. São Paulo: Atlas, 2008.

RUSSOMANO, V. H. Planejamento e controle da produção. 6. ed. São Paulo: Pioneira, 2000. 